\title{
Do papel à película: transposição da narrativa literária à fílmica por alunos do Ensino Médio
}

Adauto Locatelli Taufer ${ }^{*}$

\section{Problema de pesquisa}

O ensino da Literatura está tangenciado por uma crise, ocasionada, de um lado, por estratégias de ensino inadequadas e, por outro, pelo advento da cultura de massas e seus pseudo, ou não, benefícios, os quais foram citados por Bosi (2002), em Os estudos literários na Era dos Extremos, como: a projeção direta do prazer ou do terror, a desmaterialização da literatura pela imagem visual, a transparência que nega a mediação, a substituição dos efeitos poéticos do significado e do significante pelos efeitos imediatos e especiais da mídia, em função do interesse popular imediato, sintético, simplificado e traduzido. O uso de aparatos tecnológicos, com efeito, transformou um capítulo de um livro em uma cena de cinco minutos e, nesse processo de condensação, acabou por valorizar o enredo em detrimento da poética, o que destituiu o texto de sua função literária. Bosi busca entender a relação entre o escritor e o público nessa Era dos Extremos:

O indivíduo-massa, a personalidade construída a partir da generalização da mercadoria, quando entra no universo da escrita (o que é um fenômeno deste século), o faz com vistas ao seu destinatário, que é o leitor-massa, faminto de uma literatura que seja especular e espetacular. Autor e leitor perseguem a representação do show da vida, incrementado e amplificado. Autor-massa e leitor-massa buscam a projeção direta do prazer ou do terror, do paraíso do consumo ou do inferno do crime, de

* Professor de Língua Portuguesa e de Literatura do CAp/UFRGS. Doutor em Literatura pela UFRGS. E-mail: adautotaufer@gmail.com 
uma literatura transparente, no limite sem mediaçôes, uma literatura de efeitos imediatos e especiais, que se equipare ao cinema documentário, ao jornal televisivo, à reportagem ao vivo (...), o filme, imagem em movimento, teria tornado supérflua, para não dizer indigesta, a descrição miúda (...). Uma cena de um minuto supriria, no cinema, o que o romancista levou mais de uma dezena de páginas para compor e comunicar ao seu leitor (BOSI, 2002, p. 249).

Certamente não se pode ignorar que essa cultura de massa, produtora de adaptaçôes e best-sellers; constitua-se numa linguagem que, se por um lado, afasta os alunos da profundidade literária, por outro, é uma forma de representação que mostra a história social, que produz a arte catártica do homem contemporâneo e, por ser a linguagem que o representa é com ela que, primordialmente, estabelecerá diálogos e será nela que reconhecerá a presença do que satisfaz seus interesses e necessidades. $\mathrm{O}$ aluno lê o mundo através da TV, do cinema, do rádio, da internet. De certo modo, é a mídia que está provendo as necessidades que antes se satisfaziam na literatura. Por estar instalada essa situação, a escola precisa fazer um movimento paralelo, projetando o olhar do indivíduo para outra direção, mas sem lhe negar as linguagens que o estão educando e formando seu gosto estético e ficcional fora do contexto escolar.

Portanto, o modelo de educação proposta, como alternativa à tradicional, é aquele que tem como espinha dorsal o desenvolvimento dos adolescentes, respeitando seus interesses, estimulando-os à pesquisa e à criatividade. Na esteira desse propósito, Piaget sugere que

[...] a educação do pensamento, da razão e da própria lógica é necessária e é condição primeira da educação da liberdade. Não é suficiente preencher a memória e conhecimentos úteis para se fazer homens livres: é preciso formar inteligências ativas (PIAGET, 1998, p. 118).

Nesse sentido, entende-se que não há desenvolvimento da autonomia num ambiente em que prevalece o autoritarismo do professor, em que os alunos o veem como dono absoluto do saber. Se essa afirmativa se faz verdade, deve-se aceitar que a 
simples transmissão do saber será a prática na sala de aula. Tal maneira tradicional de ensino é o contrário da proposta neste projeto de pesquisa.

Acredita-se que - por meio de uma relação de respeito mútuo entre professor-aluno, de cooperação entre iguais e de apreço ao aluno como sujeito construtor do seu conhecimento - pode-se contribuir para a formação de indivíduos autônomos. Para isso ocorrer de modo eficaz, as atividades devem ser elaboradas de forma cooperativa: os alunos trabalhando em grupo com a interferência provocativa do professor. Dessa forma, tanto professor quanto alunos assumem a postura de pesquisadores, conforme enuncia Piaget:

[...] do ponto de vista moral, a cooperação leva não mais à mera obediência às regras impostas, sejam elas quais forem, mas a uma ética da solidariedade e da reciprocidade. Essa moral caracteriza-se, quanto à forma, pelo desabrochar do sentimento de um bem interior independente dos deveres externos, ou seja, por uma progressiva autonomia da consciência, prevalecendo sobre a heteronímia dos deveres primitivos (PIAGET, 1998, p. 118).

Dessa forma, o professor tem papel fundamental no desenvolvimento do aprendiz, uma vez que lhe cabe a tarefa de acompanhar as etapas do aprendizado de seus alunos, levando questionamentos, mas nunca oferecendo respostas prontas. Em vez disso, o orientador da aprendizagem deve sugerir, mas nunca assumir postura autoritária, como se fosse o exclusivo detentor do saber.

E qual seria, então, um possível caminho para tornar as aulas de Literatura mais atrativas aos estudantes? Será que o cruzamento entre as linguagens verbal e visual seria um meio de tornar tal disciplina mais interessante? Será que a transposição da narrativa literária à cinematográfica despertaria mais o interesse dos alunos pela e aumentaria a sua compreensão da leitura do texto literário?

Quando o assunto em pauta envolve a relação da literatura com o cinema, estabelecem-se, de antemão, questões polêmicas. 
A maior parte dos teóricos lamenta que o cinema, no afã de narrar uma história, apela à literatura, por acreditar que a película perde aquilo que chamam de "específico fílmico". Entretanto, como "[...] o que interessa ao homem é seu próprio drama que, de certa maneira, já se encontra pronto na literatura, o cinema volta-se para essa arte em busca de fundamento às histórias que ele quer contar” (CAMPOS, 2003, p. 43). Ou, então, a sétima arte apropria-se da literatura, porque ela constitui um sistema ou subsistema integrante do sistema cultural mais amplo, que permite estabelecer relações com outras artes ou mídias.

Para Johnson (2003), as relações entre o cinema e a literatura são complexas e se caracterizam, sobretudo, pela intertextualidade e, citando Avellar, diz que "[...] o que leva o cinema à literatura é uma quase certeza de que é impossível apanhar aquilo que está no livro e colocá-lo, de forma literária, no filme" (AVELLAR apud JOHNSON, 2003, p. 41). Segundo Johnson, (2003, p. 42) a "[...] insistência à fidelidade é um falso problema, porque ignora a dinâmica do campo de produção em que os meios estão inseridos".

A literatura e o cinema constituem dois campos de produção distintos cuja relação pode se tornar possível em razão da visualidade presente em determinados textos literários, permitindo sua transformação em películas. Isso implica afirmar que a literatura serve de motivo à criação de outros signos e coloca em jogo, não só a linguagem dos meios, mas também os valores subjetivos, culturais, políticos do produtor da película. Além disso, a linguagem de cada meio deve ser respeitada e "[...] apreciada de acordo com os valores do campo no qual se insere e não em relação aos valores do outro campo" (JOHNSON, 2003, p. 42). Por isso, ao se verificar as relações existentes entre o texto literário e o cinematográfico, merecem respeito às características peculiares de cada um deles, uma vez que, ao escrever um romance, o autor não o faz pensando em termos de roteiros cinematográficos; seu objetivo é, evidentemente, literário. Sendo assim, a possibilidade de transformação de um conto, uma novela ou romance para o 
cinema é uma forma de interação entre mídias, a qual dá espaço a interpretações, apropriações, redefinições de sentido. O filme passa a ser, então, apenas uma experiência formal da mudança de uma linguagem para a outra, porque o escritor e o cineasta têm sensibilidades e propósitos diferentes. Por isso, "[...] a adaptação deve dialogar não só com o texto original, mas também com seu contexto, [inclusive] atualizando o livro, mesmo quando o objetivo é a identificação com os valores neles expressos” (XAVIER, 2003, p. 62).

Aguiar (2003, p. 119) observa que grande parte das produções cinematográficas do século XX “[...] seguiu ou perseguiu enredos e personagens consolidados primeiro na literatura”. $\mathrm{O}$ estudioso acredita que isso ocorra em razão do prestígio de determinados autores e obras. Assim, estaria, em tese, assegurado o sucesso das películas provenientes de textos já consagrados. No Brasil, dentre os inúmeros filmes pautados em obras literárias, destacam-se: Macunaima (1969), de Joaquim Pedro de Andrade, baseou-se no texto homônimo de Mário de Andrade, inspirado no modernismo da Semana de 22, no qual se "[...] busca a criar uma matriz decisiva de articulação entre nacionalismo cultural e experimentação estética” (XAVIER, 2001, p. 23); A bora da estrela (1985), de Suzana Amaral, pautou-se na obra homônima de Clarice Lispector; Memórias Póstumas de Brás Cubas (2001), de André Klotzel, baseou-se em Machado de Assis; Lavoura arcaica (2001), de Luiz Fernando Carvalho, inspirou-se em obra de Raduan Nassar; Cidade de Deus (2002), de Fernando Meirelles, pautou-se no romance de Paulo Lins.

\section{Justificativa}

Partindo dessas reflexões iniciais registradas no item anterior, quer-se possibilitar a um grupo de alunos do Ensino Médio $^{5}$, do Colégio de Aplicação da UFRGS, estudar a obra de

5 Optou-se por desenvolver esse projeto de pesquisa com alunos do Ensino Médio 
arte (cinema e literatura) como um objeto estético, percebendo suas criações, seus processos de composição, suas diferentes formas de narrar, na qual se (re)concebe a catarse (que também constitui instrumento de denúncia) e o processo de (des)construção e (re)construção da identidade leitora. Para que se possam formar alunos críticos e literariamente letrados que tanto se quer, propõe-se estudar os processos narrativos da literatura e do cinema, não apenas verificando as impressões causadas, mas fazendo uma análise da sua composição; estabelecendo pontos de convergência e divergência entre essas duas artes; elaborando a escritura de roteiros a partir da leitura de textos literários e, posteriormente, realizando a filmagem desses roteiros escritos pelos alunos. Julgam-se serem esses os possíveis processos, por meio dos quais a leitura literária se efetua.

\section{Objetivos}

\section{Objetivo Geral}

- Promover o estudo da narrativa literária e seus processos de transposição para a narrativa cinematográfica, a partir da leitura de contos da literatura universal e brasileira.

\section{Objetivos Específicos}

- Abordar as diferentes formas de narrativas: verbal (contos) e visual (curtas-metragens);

- estimular o aluno a produzir conhecimento, em vez de apenas consumir informação;

- promover a escritura do roteiro de cinema (e sua posterior filmagem) a partir da leitura do texto literário;

- propiciar um ambiente favorável para o estímulo ao gosto pela leitura dos contos clássicos da literatura universal e brasileira;

porque se acredita que, neste estágio da Educação Básica, os estudantes tenham mais maturidade para o desenvolvimento da proposta. 
- realizar a transposição do texto literário para linguagem cinematográfica.

Além dos objetivos acima elencados, tem-se por meta a criação de um Núcleo de Cinema do Colégio de Aplicação. Esse núcleo implementará o Festival de Cinema na escola, no qual todos os professores que trabalham com linguagem fílmica poderão inscrever os trabalhos de seus alunos em diversas categorias de filme: documentário, curta-metragem, vídeo instrucional, dramatização de texto poético, entre outros.

\section{Método de pesquisa}

A pesquisa em educação visa a um estudo geralmente pautado nos métodos ou procedimentos que serão utilizados durante o processo. Torna-se um desafio discernir com clareza a metodologia que se pretende utilizar, uma vez que explicitar o método de pesquisa de campo é bastante importante, pois, isso define com antecedência os possíveis problemas a serem enfrentados no caminho. A preocupação com a metodologia utilizada é que ela esteja estreitamente relacionada com os objetivos, com os instrumentos utilizados e, sobretudo, que oriente a estrutura da pesquisa, desde a exposição do problema à análise dos dados e conclusões, pois sem esse rigor não há pesquisa, e sim uma visão empírica do fato. Para o desenvolvimento deste projeto de pesquisa, adotar-se-ão os seguintes procedimentos: no primeiro momento, realizar-se-á o levantamento do acervo bibliográfico pertinente ao objeto de pesquisa. Posteriormente, realizar-se-ão atividades de observaçã̃o e sondagem em relação aos alunos do $2^{\circ}$ Ano do Ensino Médio, com o intuito de saber com que frequência costumam ler livros de literatura; que tipos de livros costumam ler; que tipos de livros gostam de ler; se gostam de ler narrativas curtas; se gostam de assistir a filmes baseados em textos literários; se o filme os auxilia na compreensão da leitura do texto literário e no interesse por esse tipo de texto. 


\section{Resultados e impactos esperados}

Pretende-se, com projeto de pesquisa em questão, tornar as aulas de Literatura mais interessantes, atrativas e, sobretudo, mais próximas da realidade de nossos alunos. Deseja-se que eles se envolvam nas propostas a serem apresentadas e realizem as atividades com comprometimento, clareza e objetividade. Esperase que a transposição do texto literário ao filme desperte ainda mais o interesse e o gosto dos alunos envolvidos no projeto pela leitura dos textos literários.

Acredita-se que a abordagem proposta, com o auxílio das tecnologias que nossos alunos conhecem e dominam, tenha grande impacto social, sobretudo no que se refere à mudança comportamental dos estudantes em relação às possibilidades de exploração do texto literário. Espera-se, inclusive, que esse projeto de pesquisa seja contundente no que se circunscreve à construção do conhecimento e ao desenvolvimento de habilidades de leitura e escrita.

\section{Referências}

AGUIAR, Flávio. Literatura, cinema e televisão. In: PELLEGRINI, Tânia et al. Literatura, cinema e televisão. São Paulo: Editora Senac São Paulo: Instituto Itaú Cultural, 2003.

BOSI, Alfredo. Os estudos literários na era dos extremos. In: Literatura e resistência. São Paulo: Companhia das Letras, 2002.

CAMPOS, Fernando Coni. Cinema: sonho e lucidez. Rio de Janeiro: Azougue Editorial, 2003.

CARRIÈRE, Jean-Claude; BONITZER, Pascal. Prática do roteiro cinematográfico. São Paulo: JSN Editora, 1996.

FIELD, Syd. Manual do roteiro. Rio de Janeiro: Objetiva, 1995.

PIAGET, Jean. Sobre a pedagogia. São Paulo: Casa do Psicólogo, 1998. 
XAVIER, Ismail (Org.). A experiência do cinema: antologia. Rio de Janeiro: Graal, 1983. 